\title{
Design and optimization of HTS flux-switching permanent magnet machine
}

\author{
Ahlam Luaibi Shuraiji ${ }^{1}$, M.M.J. Al-ani ${ }^{2}$ \\ ${ }^{1}$ Electromechanical Engineering Department, University of Technology, Iraq. \\ ${ }^{2}$ Electrical and Electronic Engineering Department, University of Nottingham, U.K
}

\begin{tabular}{l}
\hline Article Info \\
\hline Article history: \\
Received Mar 17, 2019 \\
Revised May 7, 2019 \\
Accepted Jul 17, 2019 \\
\hline
\end{tabular}

\section{Keywords:}

Flux switching permanent magnet machine HTS Global optimization Superconductivity

\begin{abstract}
Flux-switching permanent magnet (FSPM) machine with high temperature superconductors (HTS) bulks located between the rotor poles to eliminate the flux leakage in the rotor, termed as (HTS-FSPM) machine has been proposed in this paper. Using genetic algorithm, the HTS and the conventional FSPM machines having the same size constraints and load conditions have been globally optimized for max aveage torque. To highlight the advantages of the HTS-FSPM machine, a performance comparison between the conventional and HTS-FSPM machines has been presented. It is found that the HTSFSPM machine can increase the torque by $27 \%$, however, this comes with the expense of higher torque ripple and power losses.
\end{abstract}

Copyright (C) 2019 Institute of Advanced Engineering and Science. All rights reserved.

\section{Corresponding Author:}

Ahlam Luaibi Shuraiji,

Departement of Electromechnical Engineering,

Uinversity of Technology,

Baghdad, Iraq.

Email: ahlamly2009@yahoo.com

\section{INTRODUCTION}

High temperature superconductors (HTS) electrical machines have been a centre of research in the past three decades, since they deliver several advantages [1-2]. High power density may be considered as the most important feature of the HTS machines [3-5]. The absence of the electrical resistivity which allows for significantly high current density and the zero magnetic permeability (Meissner effect), which offers perfect magnetic insulation opened several new electrical machine architectures with high performance.

As a type of stator permanent magnet machines, flux-swiching perment magnet (FSPM) machines have been wiedly applied in many sectors, since they incorporate the advantages of permanent magnet and reluctance machines [6-8]. However, flux leakage in stator and rotor poles is the main demerit of such machines [9]. Enhancing the exciticon system of the machine would increase the flux linkage and overcome such problem. Hence, several flux-switching permeant magnet machines with HTS field windings have been developed and reported. Conventional structure FSPM machine with HTS field winding with stationary seal has been developed and tested in [10]. Similar design with different stator structure has been studied in [11]. Furthermore, FSPM with HTS field winding located around the outer surface of the stator has been proposed in [12]. In [13] and [14], FSPM machine with HTS field winding wound radially around the stator has been designed and tested. Moreover, double rotor, linear and axial FSPM with HTS field winding has been reported in [15], [16], and [17], respectively.

Since the stator of the FSPM machine hosts all the excitation sources [18], slot area of the armature windings would be reduced when the filed winding is utilized, which results in electrical loading reduction [19]. In order to tackle such obstacle as well as reduce the flux leakage of the FSPM machine,this paper presents a FSPM machine with HTS bulks placed between the rotor poles to minize the flux leakage of the 
rotor pole, consequently improve the machine torque density. Global optimization process combining FEA and genetic algorithm has been used to optimized the machine for maximum average torque. Finally, perfromance comparison between the FSPM machine with bulk HTS and the original FSPM machine is conducted to highlight the benefits of the proposed HTS-FSPM machine.

\section{FSPM-HTS MACHINE}

The proposed HTS-FSPM machine is presented in Figure1, it consists of the same structure of the conventional FSPM machine albeit of the space between the rotor poles is filled with bulks HTS material. The bulk HTS material provides a perfect insolation for the magnetic field and therefore eliminate the flux leakage between the rotor poles and the stator and rotor. Table I lists the dimensions of the design parameters for both topologies.

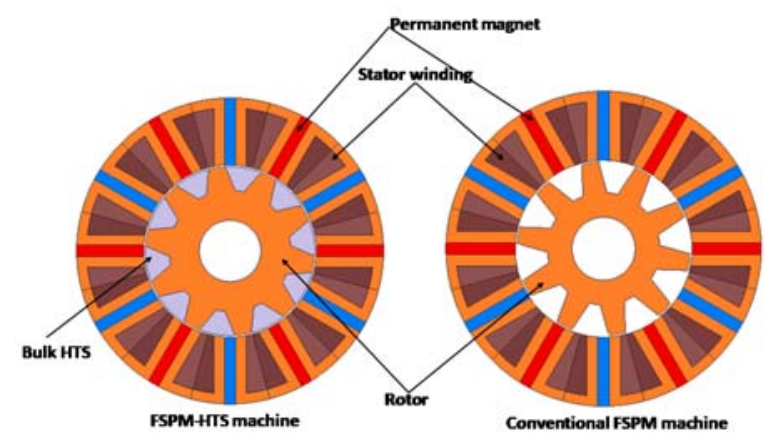

Figure 1. Cross-sections of the investigated machines, (a) FSPM-HTS, (b) conventional FSPM.

Table 1. Design parameters of the investigated FSPM machines

\begin{tabular}{cc}
\hline Main Parameters & Values \\
\hline Air gap length & $0.5 \mathrm{~mm}$ \\
Permanent magnet width & $3 \mathrm{~mm}$ \\
Stack length & $25 \mathrm{~mm}$ \\
Stator/rotor pole combination & $12 / 10$ \\
Number of turns/ phase & 72 \\
Speed & $400 \mathrm{rpm}$ \\
Current density & $12 \mathrm{~A} / \mathrm{cm} 2$ \\
\hline
\end{tabular}

\section{GLOBAL OPTIMIZATION}

Electrical machines having high torque density are desirable for various applications. Thereby, optimizing the main machine parameters for maximum torque is very important during the machine design process. It has been shown that global optimization using FEA based on Genetic Algorithm (GA) is a powerful tool to achieve such task [20]. Therefore, global optimization has been carried out for both machines to obtain maximum average torque. It should be noted that the optimization conditions have been kept the same for both machines seeking for a fair comparison. The constant parameters throughout the process of the optimization are defined in Table 1. According to [20] the parameters, which significantly effect the performance of the FSPM machine are given in Table 2. It must be mentioned that Table 2 also illustrates initial, restriction and optimal values of such parameters that have been changed in the process of the optimization, a schematic of those parameters is shown in Figure 2. The cost versus optimization iterations is shown in Figure 3. It can be seen that both machines have the same (RPTA) and (SR), while each machine possesses its own value for both (RPBA) and (RTH). On the other hand, there is a slight difference between the values of (STW) and (SBI) for both machines. 


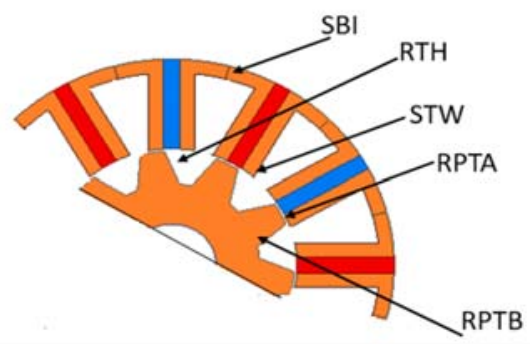

Figure 2. Schematic of varied parameters through the optimization

Table 2. Initial and optimal design parameters

\begin{tabular}{ccccc}
\hline Parameter & Initial & Restriction & \multicolumn{2}{c}{ Optimal } \\
& & & FSPM-HTS & FSPM-HTS \\
\hline Rotor pole top-arc (RPTA) & $7.5 \mathrm{deg}$. & $(4-9) \mathrm{deg}$. & 7 & 7 \\
Rotor pole bottom-arc (RPBA) & $15 \mathrm{deg}$. & $(10-18) \mathrm{deg}$. & 15.66 & 17.47 \\
Rotor teeth height (RTH) & $7 \mathrm{~mm}$ & $(6-9) \mathrm{mm}$ & 8.683 & 6.987 \\
Split ratio (SR) & 0.5 & $(0.45-0.65)$ & 0.56 & 0.56 \\
Stator tooth width (STW) & $3 \mathrm{~mm}$ & $(2-4) \mathrm{mm}$ & 3.30 & 3.10 \\
Stator back iron (SBI) & $3 \mathrm{~mm}$ & $(2-5) \mathrm{mm}$ & 2.83 & 2.93 \\
Rotor pole top-arc (RPTA) & $7.5 \mathrm{deg}$. & $(4-9) \mathrm{deg}$. & 7 & 7 \\
Rotor pole bottom-arc (RPBA) & $15 \mathrm{deg}$. & $(10-18) \mathrm{deg}$. & 15.66 & 17.47 \\
\hline
\end{tabular}

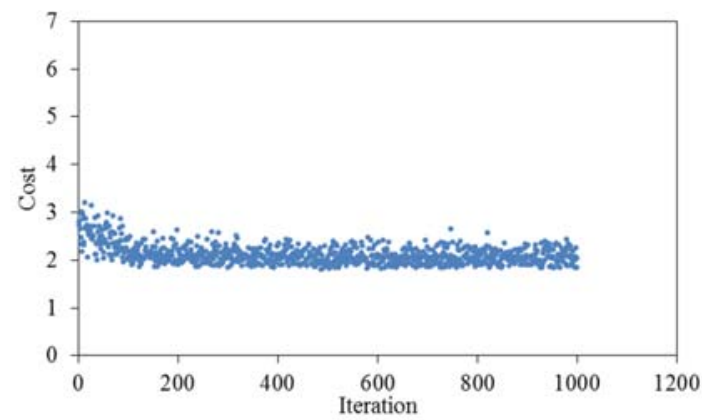

(a)

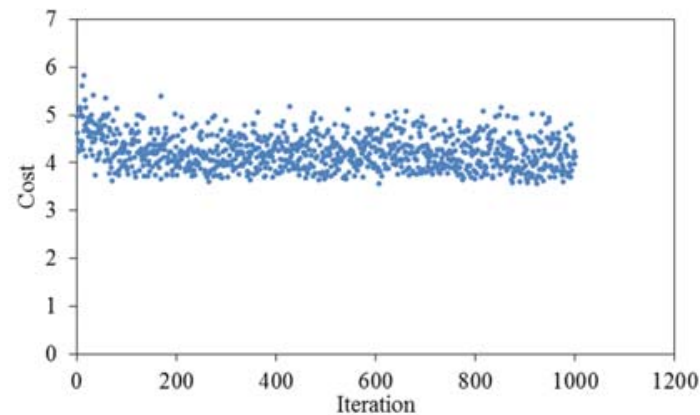

(b)

Figure 3. Optimization cost versus iterations, (a) FSPM Conv., (b) FSPM-HTS

\section{PERFORMANCE COMPARTION}

\subsection{Open-circuit results}

Flux distribution and flux density at no-load condition for the original FSPM and the HTS-FSPM machines are shown in Figure 4. Evidently the HTS-FSPM topology has no flux leakage between the rotor poles. In contrast, flux leakages are presented in the gaps between the rotor poles of the conventional FSPM machine. Thanks to the presence of the HTS material, which leads to eliminate the flux leakage between rotor poles of the proposed machine. Figure 5. compares open circuit flux linkage of phase A for the mentioned machines. As a consequent of the flux leakage elimination, the FSPM-HTS machine exhibits higher flux linkage compares to the conventional counterpart. Moreover, a comparison between back-EMFs of the pahse A for the mentioned machines is presented in Figure 6. The HTS-FSPM topology delivers about $20 \%$ higher fundamental back-EMF than that of the original FSPM counterpart, since the FSPM-HTS machine possesses higher flux linkage. Furthermore, cogging torque for both machines are given in Figure 7. Clearly, higher cogging torque is for the FSPM-HTS machine, due to high magnetic variation around its air gap. 


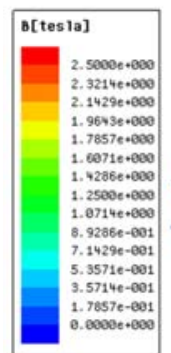

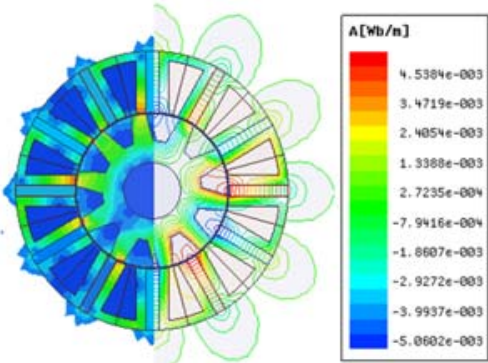

(a)
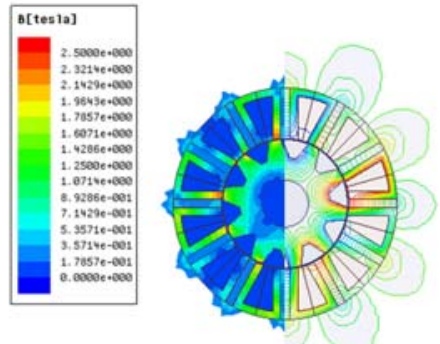

(b)

Figure4. Flux distribution and flux density, (a) FSPM Conv., (b) FSPM-HTS

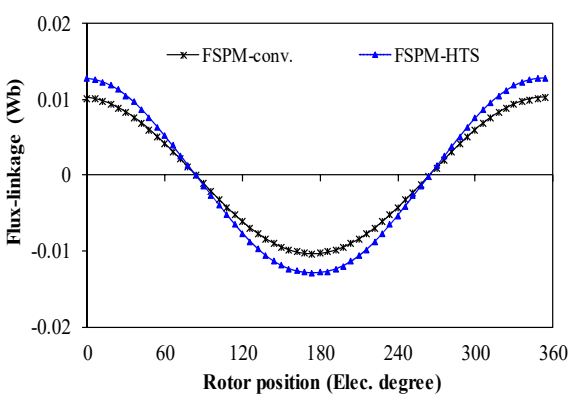

(a)

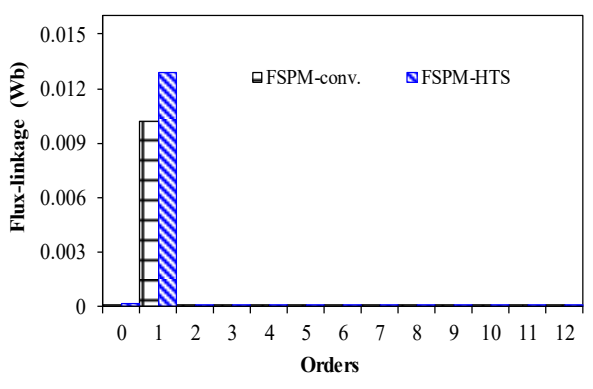

(b)

Figure5. Phase A flux linkage, (a) Waveform, (b) FFT

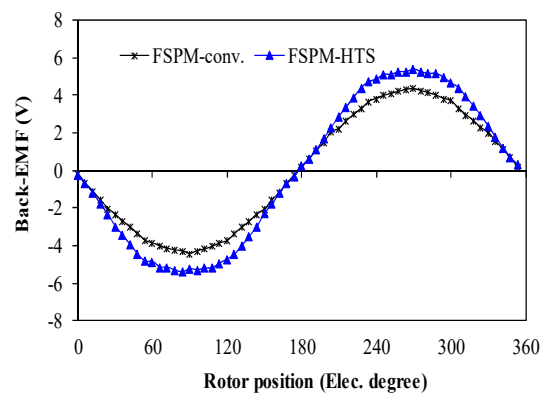

(a)

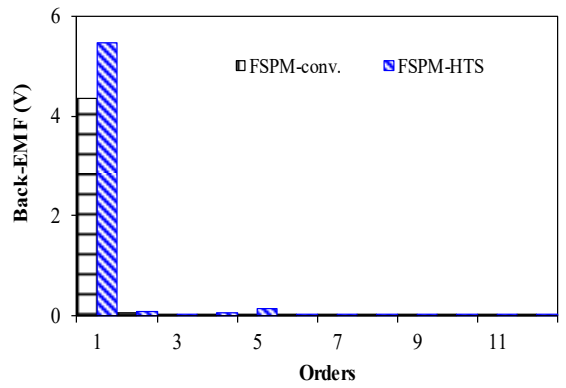

(b)

Figure 6. Phase A back-EMF, (a) Waveform, (b) FFT

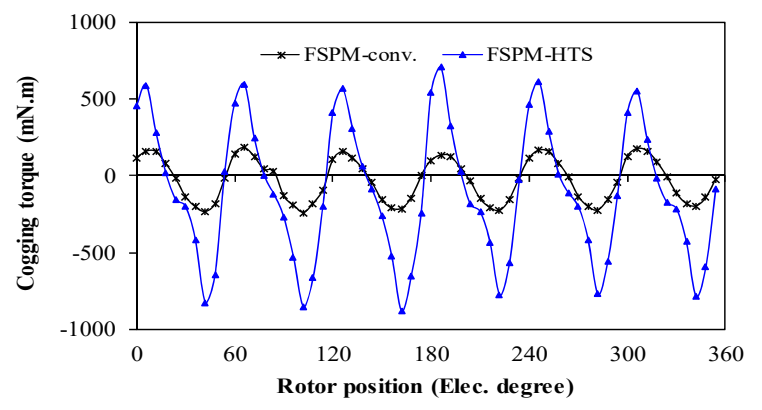

Figure 7. Cogging torque 


\subsection{Electromagnetic static torque}

The predicted 2D-FE electromagnetic static torque waveforms for one electrical cycle of the HTSFSPM and the original FSPM machines are presented in Figure 8. Apparently, the FSPM-HTS topology has higher average toque than that of the original FSPM machine, about 27\% higher average torque is obtained by the FSPM-HTS machine. In addition, Figure 9 illustrates the average electromagnetic static torque with varied current densities for the understudying machines. It can be clearly observed that at low current-density the differences between the average torques for both machines are small. In contrast, at high current-density, this difference is increased, due to the core saturation in the conventional FSPM machine.

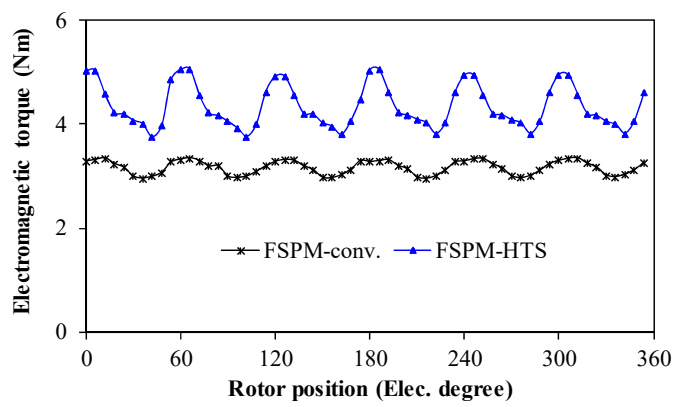

Figure 8. Electromagnetic static torque

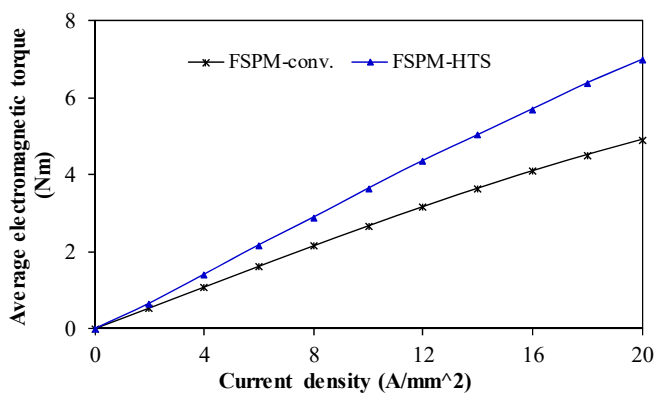

Figure 9. Average electromagnetic torque against current-density

\subsection{Electromagnetic losses}

The predicted 2D-FE losses including core and magnets eddy current losses of the understudying machines at two operating circumstances, i.e., no-load and load with current density of $12 \mathrm{~A} / \mathrm{mm} 2$ for various speed are compared in Figures 10-11, respectively. The FSPM-HTS machine has higher core and magnetic eddy current losses for both conditions in comparsion with the original FSPM machine. The losses are higher in the FSPM-HTS machine because of the higher flux focusing, which is provided by the HTS bulks. It must be mentioned that at base speed $(400 \mathrm{rpm})$ on load condition the value of core and eddy current losses for the convnetinoal machine are $(1.4 \mathrm{~W}$ and $1.4 \mathrm{w}$, respectively). In contrast, such values for the FSPM-HTS machine are $(1.5 \mathrm{~W}$ and $4 \mathrm{~W}$, respectivey), while the copper loss are $30 \mathrm{~W}$ for both machines.

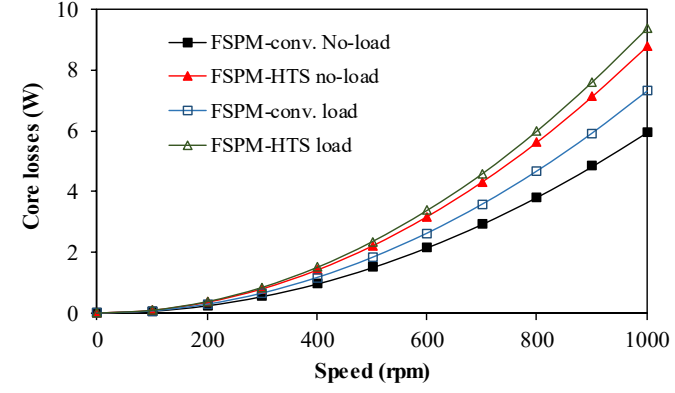

Figure 10. Core loss

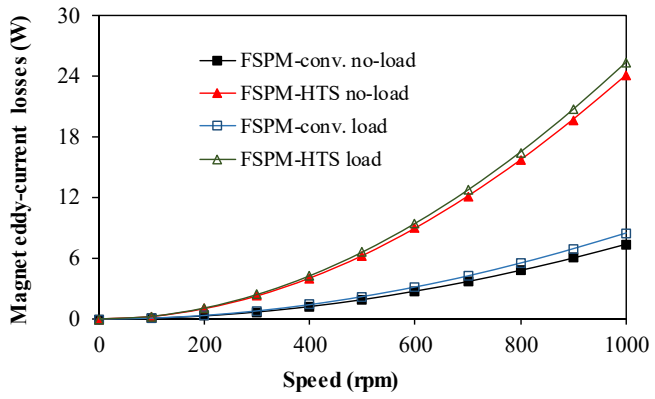

Figure 11. Magnet eddy current loss

\section{CONCLUSION}

A new FSPM with HTS bulks placed in the rotor gaps to reduce the stator-rotor flux leakage is proposed, designed, optimized and compared with the conventional FSPM machine. The conclusions of this work are:

By adding HTS bulks in the rotor poles gaps of the FSPM machine, the average torque can improve by $27 \%$ compared to the conventional FSPM counterpart, keeping in consideration that both machines are globally optimized. While, the torque ripple of the proposed machine is around twice of the conventional, since high magnetic variation around the air gap appears when the HTS bulks are used. Moreover, higher

Design and optimization of HTS flux-switching permanent magnet machine (Ahlam. Luaibi Shuraiji) 
core and magnet loss are found in the proposed machine because of the higher magnetic flux focusing and therefore saturation.

\section{REFERENCES}

[1] J. Gieras, "Superconducting Electrical Machines State of the Art," Przeglad Elektrotechniczny, Vol. 85, pp. 1-19, 2009.

[2] R. Qu, Y. Liu and J. Wang, "Review of Superconducting Generator Topologies for Direct-Drive Wind Turbines," in IEEE Transactions on Applied Superconductivity, vol. 23, no. 3, pp. 5201108-5201108, June 2013.

[3] L. K. Kovalev et al., "High Output Power Reluctance Electric Motors with Bulk HTS Elements," in Proc. of the Fifth International Conference on Electrical Machines and Systems (ICEMS), pp. 929-933, China, 2001.

[4] K. Sivasubramaniam et al., "Development of a High Speed HTS Generator for Airborne Applications," in IEEE Transactions on Applied Superconductivity, vol. 19, no. 3, pp. 1656-1661, June 2009.

[5] R. Shafaie, F. Amirkhanloo and M. Kalantar, "Toward an Optimum Design of Large-Scale HTS Synchronous Generator for Wind Turbine Applications," in IEEE Transactions on Applied Superconductivity, vol. 26, no. 2, pp. 1-8, March 2016.

[6] W. Hua, Z. Q. Zhu, M. Cheng, Y. Pang, and D. Howe, "Comparison of Flux-switching and Doubly-salient Permanent Magnet Brushless Machines," in Proc. of the Eighth International Conference on Electrical Machines and Systems, (ICEMS), pp. 156-170, China, September 2005.

[7] R. Kumar, E. Sulaiman, M. Jenal, L. Iwani Jusoh, and F.S. Bahrim, "Design and Investigation of Outer Rotor Permanent Magnet Flux Switching Machine for Downhole Application," in International Journal of Power Electronics and Drive System (IJPEDS), Vol. 8, No. 1, pp. 231-238, March 2017.

[8] M. Cheng, W. Hua, J. Zhang and W. Zhao, "Overview of Stator-Permanent Magnet Brushless Machines," in IEEE Transactions on Industrial Electronics, vol. 58, no. 11, pp. 5087-5101, November 2011.

[9] C. Liu, K. T. Chau, J. Z. Jiang and S. Niu, "Comparison of Stator-Permanent-Magnet Brushless Machines," in IEEE Transactions on Magnetics, vol. 44, no. 11, pp. 4405-4408, November 2008.

[10] Y. Wang, Q. Feng, X. Li and W. Ma, "Design, Analysis, and Experimental Test of a Segmented-Rotor High Temperature Superconducting Flux-Switching Generator with Stationary Seal," in IEEE Transactions on Industrial Electronics. vol. 65, no. 11, pp. 9047-9055, November 2018.

[11] Y. Wang, J. Sun, Z. Zou, Z. Wang and K. T. Chau, "Design and Analysis of a HTS Flux-Switching Machine for Wind Energy Conversion," in IEEE Transactions on Applied Superconductivity, vol. 23, no. 3, pp. 50009045000904, June 2013.

[12] J. Rao and W. Xu, "Modular Stator High Temperature Superconducting Flux-Switching Machines," in IEEE Transactions on Applied Superconductivity, vol. 24, no. 5, pp. 1-5, October 2014.

[13] J. M. Kim, J. Y. Jang, S. Lee and Y. J. Hwang, "Characteristic Analysis of an HTS Flux-Switching Synchronous Generator with NI-Type HTS Field Coils," in IEEE Transactions on Applied Superconductivity, vol. 28, no. 3, pp. 1-5, April 2018.

[14] Y. J. Hwang et al., "Electromagnetic Design of a 15 MW-Class HTS Flux Switching Synchronous Generator Considering Mechanical Stress of the Rotor Core," in IEEE Transactions on Applied Superconductivity, vol. 24, no. 3, pp. 1-5, June 2014.

[15] X. Li, S. Liu and Y. Wang, "Design and Analysis of a New HTS Dual-Rotor Flux-Switching Machine," in IEEE Transactions on Applied Superconductivity, vol. 27, no. 4, pp. 1-5, June 2017.

[16] R. Cao, Y. Jin, Y. Zhang and M. Cheng, "A New Double-Sided HTS Flux-Switching Linear Motor with Series Magnet Circuit," in IEEE Transactions on Applied Superconductivity, vol. 26, no. 7, pp. 1-5, October 2016.

[17] Y. Wang, M. Chen, T. W. Ching and K. T. Chau, "Design and Analysis of a New HTS Axial-Field FluxSwitching Machine," in IEEE Transactions on Applied Superconductivity, vol. 25, no. 3, pp. 1-5, June 2015.

[18] J. T. Chen and Z. Q. Zhu, "Winding Configurations and Optimal Stator and Rotor Pole Combination of FluxSwitching PM Brushless AC Machines," in IEEE Transactions on Energy Conversion, vol. 25, no. 2, pp. 293 302, June 2010.

[19] J. T. Chen, Z. Q. Zhu, S. Iwasaki and R. P. Deodhar, "A Novel Hybrid-Excited Switched-Flux Brushless AC Machine for EV/HEV Applications," in IEEE Transactions on Vehicular Technology, vol. 60, no. 4, pp. 1365 1373, May 2011.

[20] Z. Q. Zhu and X. Liu, "Individual and global optimization of switched flux permanent magnet motors," in Proc. IEEE Electrical Machines and Systems Conf., pp.1-6, 2011. 


\section{BIOGRAPHIES OF AUTHORS}

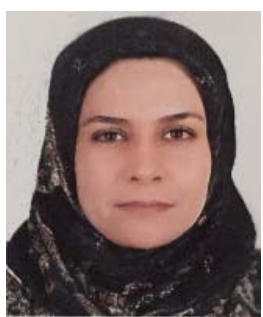

Ahlam Luaibi. Shuraiji received the B.Eng. and M.Sc. degrees in Engineering Educational Technology/ Electrical Engineering, from University of Technology, Baghdad, Iraq, in 1998 and 2004, respectively, and the Ph.D. degree in electrical engineering from The University of Sheffield, Sheffield, U.K., in 2017. She is currently a lecturer at the University of Technology/ Electromechanical Engineering department. Her research interests include the design of permanent-magnet machines

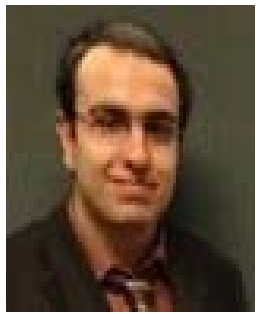

M. M. J. Alani received the Eng. and the Ph.D. degree in electrical engineering from The University of Sheffield, Sheffield, U.K., in 2010 and 2014, respectively. He is currenty a Research Fellow at University of Nottingham. His research interests include permanent magnet machines design and drive. 